\title{
SCIENTIFIC COMMENTARY
}

\section{Intrasubject Variation in Elimination Half-Lives of Drugs Which Are Appreciably Metabolized}

\author{
John G. Wagner ${ }^{1}$
}

\section{INTRODUCTION}

It is sometimes assumed in evaluating data from some pharmacokinetic and pharmacogenetic studies that the half-life of elimination of a drug which is appreciably or essentially completely metabolized by man is essentially a constant for a given individual subject. I have run a large number of carefully controlled crossover studies in so-called normal subjects during the past 10 years. The impression gained from these studies is that there is appreciable intrasubject variation in half-lives of elimination. The magnitude of intrasubject and intersubject variation in half-lives of elimination is apparently drug specific and needs to be checked out with each drug. Some of the results obtained over the past 10 years are described below.

\section{CLINDAMYCIN}

Clindamycin is a semisynthetic antibiotic, namely, $7(S)$-chloro-7deoxylincomycin hydrochloride hydrate. Novak et al. (1) reported serum concentrations of clindamycin in ten adult male volunteers following intramuscular administration of $1,1.5$, and $2 \mathrm{ml}$ doses of a sterile solution of the hydrochloride salt containing a label of $100 \mathrm{mg}$ of base equivalent per milliliter. The half-life of each subject following each treatment was estimated from those terminal serum concentrations which appeared to be randomly distributed about a straight line when the serum concentrations were plotted on semilogarithmic graph paper. The half-life $\left(t_{1 / 2}\right)$ was estimated from equation 2 following least-squares regression analysis employing equation 1 :

$$
\begin{aligned}
\ln C & =\ln C_{0}-K t \\
t_{1 / 2} & =0.693 / K
\end{aligned}
$$

\footnotetext{
${ }^{1}$ Upjohn Center for Clinical Pharmacology, The University of Michigan, Ann Arbor, Michigan
} 48104. 
Table I. Half-Lives of Elimination of Clindamycin in Ten Normal Male Adult Volunteers

\begin{tabular}{|c|c|c|c|c|c|c|}
\hline \multirow[b]{2}{*}{ Subject } & \multicolumn{2}{|c|}{$1 \mathrm{ml}$ dose } & \multicolumn{2}{|c|}{$1.5 \mathrm{ml}$ dose } & \multicolumn{2}{|c|}{$2.0 \mathrm{ml}$ dose } \\
\hline & Dose $(\mathrm{mg} / \mathrm{kg})$ & $t^{1 / 2}(\mathrm{hr})$ & Dose $(\mathrm{mg} / \mathrm{kg})$ & $t^{1 / 2}(\mathrm{hr})$ & Dose $(\mathrm{mg} / \mathrm{kg})$ & $t^{1 / 2}(\mathrm{hr})$ \\
\hline 1 & 1.86 & 3.20 & 2.79 & 4.02 & 3.72 & 3.50 \\
\hline 2 & 1.07 & 5.20 & 1.60 & 3.92 & 2.13 & 4.58 \\
\hline 3 & 1.71 & 2.95 & 2.56 & 4.04 & 3.42 & 3.56 \\
\hline 4 & 1.54 & 2.53 & 2.31 & 2.88 & 3.08 & 4.73 \\
\hline 5 & 1.25 & 6.68 & 1.87 & 6.24 & 2.50 & 6.34 \\
\hline 6 & 1.73 & 3.07 & 2.60 & 3.52 & 3.47 & 3.49 \\
\hline 7 & 1.35 & 7.06 & 2.03 & 4.38 & 2.70 & 4.37 \\
\hline 8 & 1.25 & 5.14 & 1.87 & 5.19 & 2.50 & 6.83 \\
\hline 11 & 1.31 & 7.74 & 1.96 & 4.87 & 2.61 & 5.97 \\
\hline 12 & 1.16 & 4.68 & 1.74 & 5.53 & 2.32 & 6.66 \\
\hline
\end{tabular}

Results are shown in Table I. It may be seen that there is considerable intrasubject variation in the $t_{1 / 2}$ values. The analysis of variance of the half-lives shown in Table $I$ is given in Table II. The failure of the treatment mean square to be significant suggests strongly that the $t_{1 / 2}$ estimation was not influenced by the dose of clindanycin administered. There was a significant intersubject variation in $t_{1 / 2}$, as evidenced by the significant mean square for subjects. The residual mean square is a measure of intrasubject variation in the $t_{1 / 2}$ plus unexplained error. The coefficient of variation calculated by equation 3 below was $19.9 \%$.

In a nother study reported by Wagner et al. (2), $150 \mathrm{mg}$ doses of clindamycin base equivalent were administered orally as the hydrochloride salt in both tablets and capsules in a 12 subject crossover study. Half-lives could be estimated in ten subjects from serum concentrations measured by an extraction-microbiological assay. Ten half-lives estimated following administration of the capsule averaged $2.55 \mathrm{hr}$, with a standard deviation of $0.94 \mathrm{hr}$. Ten half-lives estimated following administration of the tablet averaged $2.21 \mathrm{hr}$, with a standard deviation of $0.48 \mathrm{hr}$. The difference between these averages was not significant $(p>0.10)$, suggesting strongly that continued absorption from the dosage forms was not biasing one set of

Table II. Analysis of Variance of Half-Lives of Elimination of Clindamycin Shown in Table I

\begin{tabular}{lrrccc}
\hline $\begin{array}{l}\text { Source of } \\
\text { variation }\end{array}$ & df & SS & MS & $F$ & $P$ \\
\hline Total & 29 & 58.389 & - & - & - \\
Treatments & 2 & 1.539 & 0.770 & 0.862 & $P>0.25$ \\
Subjects & 09 & 40.779 & 4.531 & 5.07 & $0.005>P>0.001$ \\
Residual & 18 & 16.072 & 0.893 & - & \\
\hline
\end{tabular}




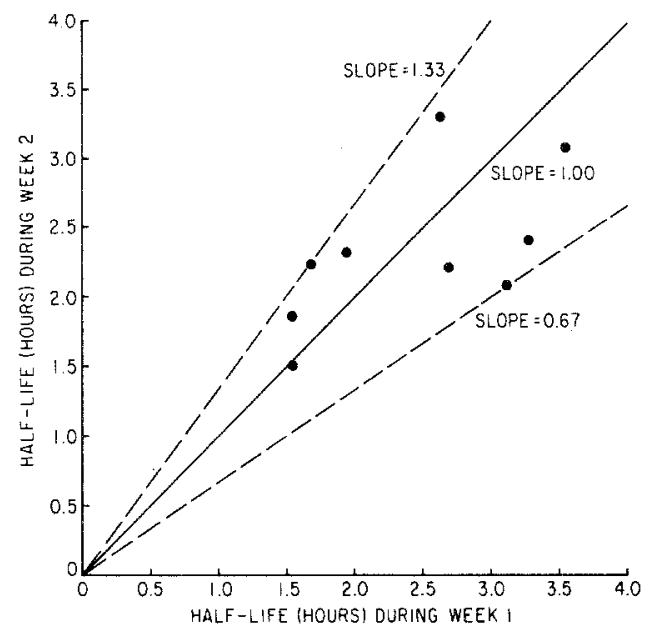

Fig. 1. A plot of the half-life of clindamycin after oral administration from serum concentration data obtained during week 2 (phase II) against the half-life obtained during week 1 (phase I) for the same nine subjects. The plot shows that the ratio (half-life during week 2)/(half-life during week 1) varied from 0.67 to 1.33 with an average of 1.0 .

half-lives more than the other. In Fig. 1, the half-life estimated from the week 2 (phase II) data is plotted against the half-life estimated from the week 1 (phase I) data for nine subjects. The intrasubject variation in $t_{1 / 2}$ is obvious.

The overall mean $t_{1 / 2}$ of clindamycin following intramuscular administration (data in Table I) is $4.76 \mathrm{hr}$. The overall mean $t_{1 / 2}$ of clindamycin following oral administration is $2.38 \mathrm{hr}$ (2). The slope of the plot of area under the serum concentration $\mathrm{vs} . \mathrm{mg} / \mathrm{kg}$ dose following intramuscular administration is 10.3 (1). The average area under the serum concentration curve following $150 \mathrm{mg}$ oral doses as tablets or capsules is $10.9(\mu \mathrm{g} / \mathrm{ml}) \times \mathrm{hr}$ in a panel with average body weight of $75.3 \mathrm{~kg}$, giving a ratio of $5.48(\mu \mathrm{g} / \mathrm{ml})$ $\times$ hr per $1 \mathrm{mg} / \mathrm{kg}$ clindamycin base administered. Hence the doubling of the half-life of clindamycin when given intramuscularly compared with orally is reflected in an approximate doubling of the area (since $10.3 / 5.48=1.9$ ). Hence the "route of administration" effect can be very important with certain drugs.

\section{WARFARIN}

Wagner et al. (3) listed plasma concentrations of warfarin, measured by both a thin layer chromatographic method and an extraction method, in six 
Table III. Half-Lives of Warfarin in Hours Estimated from Terminal Plasma Concentrations ${ }^{a}$ Measured by Modified O'Reilly Assays and TLC Assays on Same Samples ${ }^{b}$

\begin{tabular}{|c|c|c|c|c|c|c|}
\hline \multirow[b]{2}{*}{ Subject } & \multicolumn{3}{|c|}{$\begin{array}{c}\text { Treatment } \mathrm{A} \\
\text { (five } 5 \mathrm{mg} \text { tablets) }\end{array}$} & \multicolumn{3}{|c|}{$\begin{array}{c}\text { Treatment B } \\
\text { (one } 25 \mathrm{mg} \text { tablet) }\end{array}$} \\
\hline & TLC & O'Reilly & $\begin{array}{c}\text { Normalized } \\
\text { difference }^{c} \\
(\%)\end{array}$ & TLC & O'Reilly & $\begin{array}{c}\text { Normalized } \\
\text { difference } \\
(\%)\end{array}$ \\
\hline 1 & 33.6 & 28.8 & -15.4 & 35.1 & 34.3 & -2.3 \\
\hline 2 & 24.6 & 27.1 & 9.7 & 29.9 & 29.7 & -0.7 \\
\hline 3 & 34.8 & 47.2 & 30.2 & 42.7 & 55.0 & 25.2 \\
\hline 4 & 26.8 & 33.7 & 22.8 & 29.5 & 26.2 & -11.8 \\
\hline 5 & 40.8 & 31.1 & -27.0 & 41.4 & 56.9 & 31.5 \\
\hline 6 & - & - & - & 33.7 & 34.5 & 2.3 \\
\hline $6 a$ & 49.5 & 44.2 & -11.3 & - & - & - \\
\hline \multirow[t]{3}{*}{ Averages } & $35.0^{d}$ & $35.4^{d}$ & 1.5 & $35.4^{e}$ & $39.4^{e}$ & 7.4 \\
\hline & & & TLC & O'Reilly & $\begin{array}{c}\text { Normalized } \\
\text { difference }(\%)\end{array}$ & \\
\hline & \multicolumn{2}{|c|}{ Overall averages } & $35.2^{f}$ & $37.4^{f}$ & 4.5 & \\
\hline
\end{tabular}

"Half-lives were estimated by obtaining the slope of line, by the method of least squares, when $\ln C_{p}$ is plotted is. $t$, and dividing the absolute value of the slope into 0.693 . Only plasma concentrations corresponding to times equal to or greater than $24 \mathrm{hr}$ were employed.

${ }^{b}$ Data plotted in Fig. 4 of Welling et al. (6).

' Normalized difference equals half-life from O'Reilly assays minus half-life from TLC assays divided by average half-life from O'Reilly and TLC assays $\times 100$.

${ }^{d}$ Difference in averages is not significant by paired $t$-test $(t=0.097, p>0.25)$.

${ }^{e}$ Difference in a verages is not significant by paired $t$-test $(t=1.27, p>0.10)$.

${ }^{f}$ Difference in averages is not significant by paired $t$-test $(f=0.95 . p>0.25)$.

normal volunteers following oral administration of $25 \mathrm{mg}$ doses of warfarin sodium as five $5 \mathrm{mg}$ tablets and one $25 \mathrm{mg}$ tablet. Half-lives of warfarin estimated from these plasma concentrations were summarized by Wagner (4) and are presented again in Table III. The modified O'Reilly (extraction) assay method gave a longer half-life in six trials, but the TLC assay gave a longer half-life in exactly six other trials. The difference in average half-lives obtained by the two methods was not significant. The statistics presented in Table III also indicate that the particular tablets administered did not affect the half-lives obtained. There is intrasubject variation in half-lives, however. This is emphasized further by the data in Table IV, taken from Wagner (5). This table lists half-lives of warfarin in four normal volunteers who took part in two different crossover studies in which warfarin was dosed orally as commercial tablets of different types. The half-lives recorded in Table IV were not significantly correlated with the dose number, the dosing day number, or the dose administered. There was also strong pharmacokinetic evidence that absorption of warfarin had ceased sometime before the 
Table IV. Warfarin Half-Lives Estimated from Terminal Plasma Concentrations for Four Subjects Common to Two Clinical Studies

\begin{tabular}{|c|c|c|c|c|c|c|}
\hline \multirow[b]{3}{*}{ Subject } & \multicolumn{5}{|c|}{ Half-life (hr) } & \multirow[b]{3}{*}{ C.V. $(\%)$} \\
\hline & \multicolumn{2}{|c|}{ Study No. 1} & \multicolumn{3}{|c|}{ Study No. 2} & \\
\hline & Phase I & Phase II & Phase I & Phase II & Phase III & \\
\hline $\mathrm{B}$ & $26.6^{a}$ & $33.7^{b}$ & $51.3^{c}$ & $46.9^{c}$ & $42.0^{c}$ & 24.9 \\
\hline$C^{r}$ & $47.2^{b}$ & $55.0^{a}$ & $59.9^{c}$ & $34.1^{c}$ & $34.5^{c}$ & 25.4 \\
\hline $\mathrm{C}^{\mathrm{h}}$ & $56.9^{a}$ & $31.1^{b}$ & $52.1^{c}$ & $56.8^{\mathrm{c}}$ & $74.5^{\mathrm{c}}$ & 28.6 \\
\hline $\mathrm{R}$ & $28.8^{b}$ & $34.3^{a}$ & $59.9^{c}$ & $42.7^{c}$ & $76.8^{c}$ & 40.6 \\
\hline Dose $\mathrm{Nc}$ & 1 & 2 & 3 & 4 & 5 & - \\
\hline Dosing & o. 1 & 22 & 64 & 85 & 106 & - \\
\hline
\end{tabular}

a One $25 \mathrm{mg}$ tablet.

${ }^{b}$ Five $5 \mathrm{mg}$ tablets.

'Two $5 \mathrm{mg}$ tablets.

first sampling time which was used to estimate the half-life. In these studies, intrasubject variation in half-life was approximately the same as intersubject variation in half-life. The coefficients of variation listed in the last column of Table IV give an indication of the magnitude of intrasubject variation of the half-life of warfarin.

\section{EPHEDRINE}

Half-lives of ephedrine in man. estimated from the urinary excretion data of Welling et al. (6), and summarized by Wagner (5), are reproduced in Table V. An analysis of variance of the data in Table V is given in Table VI.

Table V. Intrasubject Variation in Half-Life of Ephedrine Following Single Oral Doses of $25 \mathrm{mg}$ Ephedrine Sulfate to Three Adult, Nonsmoking Male Volunteers

\begin{tabular}{|c|c|c|c|c|c|c|}
\hline \multirow[b]{2}{*}{ Subject } & \multicolumn{2}{|c|}{ Treatment $\mathrm{A}^{a}$} & \multicolumn{2}{|c|}{ Treatment $\mathbf{B}^{b}$} & \multicolumn{2}{|c|}{ Treatment $\mathbf{C}^{c}$} \\
\hline & $t_{1 / 2}$ No. $1^{d}$ & $t_{1 / 2}$ No. $2^{e}$ & $t_{1 / 2}$ No. 1 & $t_{1 / 2}$ No. 2 & $t_{1 / 2}$ No. 1 & $t_{1 / 2}$ No. 2 \\
\hline 1 & 7.46 & 7.17 & 7.35 & 5.33 & 5.14 & 5.27 \\
\hline 2 & 5.35 & 5.93 & 6.71 & 5.27 & 5.01 & 4.94 \\
\hline 3 & 5.15 & 5.25 & 6.08 & 5.92 & 5.69 & 5.77 \\
\hline
\end{tabular}

a Treatment A was Ephedrine Sulfate Syrup (Eli Lilly \& Co.).

${ }^{b}$ Treatment B was Ephedrine Sulfate Capsules $25 \mathrm{mg}\left(\frac{3}{8} \mathrm{gr}\right)$ (Eli Lilly \& Co.).

- Treatment $\mathrm{C}$ was Ephedrine Sulfate Capsules $25 \mathrm{mg}\left(\frac{3}{8} \mathrm{gr}\right.$ ) (American Pharmaceutical Co.).

${ }^{i} t_{1 / 2}$ No. 1 is $0.693 / \beta$, where $\beta$ was obtained by fitting all data of each subject on each treatment to the two-compartment open model with first-order absorption.

${ }^{e} t_{1 / 2}$ No. 2 was obtained from terminal excretion rates only by the method of least squares applied to In (excretion rate) vs. time. 
Table VI. Analysis of Variance of Half-Lives of Ephedrine Shown in Table V

\begin{tabular}{lrrccc}
\hline $\begin{array}{l}\text { Source of } \\
\text { variation }\end{array}$ & df & SS & MS & $F$ & $P$ \\
\hline Total & 17 & 11.487 & - & - & $-\bar{P}>0.10$ \\
$\quad \begin{array}{l}\text { Treatments } \\
\text { Subjects }\end{array}$ & 2 & 2.428 & 1.214 & 2.22 & $0.25>0.25>P>0.10$ \\
$\begin{array}{l}\text { Method of } \\
\quad \text { obtaining } t_{1 / 2}\end{array}$ & 1 & 1.981 & 0.991 & 1.82 & 0.25 \\
$\quad$ Residual & 12 & 0.530 & 0.530 & 0.97 & $P>0.25$ \\
\hline
\end{tabular}

The mean squares for treatments, subjects, and methods of obtaining the $t_{1 / 2}$ values are all not significant. The residual mean square is $55 \%$ of the between-subject mean square. The residual mean square is a measure of intrasubject and unexplained variation. The coefficient of variation, calculated from the grand mean and the residual mean square (RMS) by equation 3 ,

$$
\text { C.V. }(\%)=(\sqrt{\mathrm{RMS}} / \text { grand mean }) \times 100
$$

is $12.7 \%$.

\section{LINCOMYCIN}

Wagner et al. (7) reported on half-ives of the antibiotic lincomycin observed in repetitive studies on the same subjects. These data were extended and summarized by Wagner (5) and are reproduced as Table VII. After solution and capsule treatments, the median half-lives were, study II, 4.38 and 4.55 ; study III, 4.87 and $4.36 \mathrm{hr}$, respectively. This and other analysis of the data indicated that the dosage form per se was not influencing the halflife estimated, as would be expected if there were absorption still occurring when the half-lives were estimated. The half-life of lincomycin in some subjects is quite reproducible from study to study, as can be seen by the data for subjects $\mathrm{B}$ and $\mathrm{P}$ in Table VII. However, other subjects, such as $\mathrm{H}$ and $\mathrm{E}$, show considerable intrasubject variation in half-life.

\section{ETHOSUXIMIDE}

Buchanan et al. (8) administered ethosuximide in syrup and capsule dosage forms to the same four children at different times. Elimination halflives were estimated from terminal plasma concentrations. Their data are summarized in Table VIII. The half-lives were quite reproducible in subjects 1,2 , and 4 but not in subject 3 . 
Table VII. Intrasubject Variation in Half-Life ${ }^{a}$ of Lincomycin Observed in Repetitive Studies in the Same Six Adult Male Subjects After Oral Administration of Lincomycin Hydrochloride in Rapidly Dissolving Capsules or in Aqueous Solution

\begin{tabular}{|c|c|c|c|c|c|c|c|c|}
\hline \multirow[b]{2}{*}{ Study } & \multirow[b]{2}{*}{ Date } & \multicolumn{6}{|c|}{ Subject } & \multirow{2}{*}{$\begin{array}{c}\text { Date } \\
\text { median }\end{array}$} \\
\hline & & $\mathrm{H}$ & $\mathrm{E}$ & $\mathrm{C}$ & K & B & $P$ & \\
\hline \multirow{2}{*}{ I } & $\{2 / 18 / 64$ & - & $6.13^{b}$ & - & $5.36^{b}$ & - & $4.26^{b}$ & 5.36 \\
\hline & $2 / 25 / 64$ & $13.8^{b}$ & - & 5.37 & - & $4.47^{b}$ & - & 5.37 \\
\hline \multirow{2}{*}{ II } & $\int 3 / 24 / 64$ & $4.00^{c}$ & $4.2^{c}$ & 4.43 & 5.22 & 5.22 & $4.51^{c}$ & 4.47 \\
\hline & $\{3 / 31 / 64$ & $5.90^{b}$ & 5.62 & $4.80^{c}$ & $4.55^{c}$ & $4.19^{c}$ & $4.55^{b}$ & 4.68 \\
\hline \multirow{3}{*}{ III } & $\{5 / 19 / 64$ & $7.86^{d}$ & $8.43^{e}$ & $5.15^{e}$ & $4.24^{d}$ & $4.59^{e}$ & $4.47^{d}$ & 4.87 \\
\hline & $5 / 26 / 64$ & $9.69^{e}$ & $4.90^{d}$ & $4.22^{d}$ & 4.09 & $4.18^{d}$ & $4.14^{e}$ & 4.20 \\
\hline & Median & 7.86 & 5.62 & 4.80 & 4.55 & 4.47 & 4.51 & 4.60 \\
\hline
\end{tabular}

${ }^{a}$ Equations 1 and 2 were employed. Usually the 8, 10, 12, and 14 or the 10, 12, and $14 \mathrm{hr}$ points were used.

${ }^{b}$ Formulation 1 (median half-life $5.29 \mathrm{hr}$ ).

' Formulation 2 (median half-life $4.38 \mathrm{hr}$ ).

${ }^{d}$ Formulation 3 (median half-life $4.36 \mathrm{hr}$ ).

${ }^{e}$ Formulation 4 (median half-life $4.87 \mathrm{hr}$ ).

\section{ETHANOL}

Vesell et al. (9) measured apparent zero-order rates of ethanol metabolism in fraternal and identical twins only once in each subject and found that the interpair differences were significantly greater in fraternal twins than in identical twins. They stated that their "investigation did not test the possibility of day-to-day variations of alcohol metabolism within the same subject," yet they calculated that the contribution of hereditary to individual differences in ethanol metabolism was 0.98 out of 1.0. In the same paper, they did report apparent zero-order rates of ethanol metabolism in six male volunteers before and after ingestion of $1 \mathrm{ml}$ of $95 \%$ alcohol per kilogram

Table VIII. Half-Lives of Ethosuximide in the Same Four Children as Reported by Buchanan et al. (8)

\begin{tabular}{cccc}
\hline & & \multicolumn{2}{c}{ Half-life (hr) } \\
\cline { 3 - 4 } Subject & Body weight $(\mathrm{lb})$ & Syrup & Capsule \\
\hline \multirow{2}{*}{1} & 30.0 & 24.8 & 25.7 \\
2 & 40.0 & 31.8 & 30.0 \\
3 & 37.0 & 37.3 & 26.9 \\
4 & 28.5 & 31.6 & 30.1 \\
\hline
\end{tabular}


Table IX. Apparent Zero-Order Rates of Ethanol Metabolism in Six Male Volunteers Before and After Chronic Alcohol Administration ${ }^{a}$

\begin{tabular}{|c|c|c|c|}
\hline \multicolumn{4}{|c|}{ Apparent zero-order rate $[\mathrm{mg} /(\mathrm{ml} \times \mathrm{hr})]$} \\
\hline Subject & Before & After & Percent change \\
\hline A.M. & 0.186 & 0.200 & +7.5 \\
\hline C.G. & 0.203 & 0.255 & +25.6 \\
\hline E.W. & 0.200 & 0.195 & -2.5 \\
\hline G.P. & 0.223 & 0.180 & -19.3 \\
\hline M.M. & 0.122 & 0.235 & +92.6 \\
\hline \multirow[t]{3}{*}{ R.G. } & 0.192 & 0.180 & -6.3 \\
\hline & $0.188^{b}$ & $0.208^{b}$ & \\
\hline & 18.4 & 14.8 & \\
\hline
\end{tabular}

${ }^{a}$ One milliliter $95 \%$ ethanol per kilogram body weight per day for 21 days as reported by Vesell et al. (9).

${ }^{b}$ Paired $t$-test gave $t=0.88(p>0.25)$.

of body weight per day for 21 days. These data are summarized in Table IX. The mean rates of 0.188 and 0.208 were not significantly different by a paired $t$-test, but there were relatively large differences in the "before" and "after" rates in three of the six subjects, as indicated by the last column in Table IX.

It should be pointed out that the formula used by Vesell et al. (9) to estimate the hereditary component assumes no intrasubject variation in clearance rate of a drug. It is the author's opinion that such pharmacogenetic studies should include repeated measurements in the same subjects and use of a more complicated formula for estimating the hereditary component.

Wagner and Patel (10) reported capillary blood ethanol concentrations measured in the same normal adult volunteer when he was given three different doses of ethanol in five different controlled trials. The estimated volume of distribution of ethanol had a coefficient of variation of $12 \%$. However, the estimated apparent zero-order rates of ethanol metabolism had a coefficient of variation of $26.7 \%$. They also estimated $V_{m}$ and $K_{m}$ values by direct computer fitting of the terminal alcohol blood concentrations to the integrated form of the Michaelis-Menten equation. The estimated $V_{m}$ values had coefficients of variation of 50.5 and $45.3 \%$, and the estimated $K_{m}$ values had coefficients of variation of 98.3 and $97.3 \%$, depending on which estimates were included. It should be particularly emphasized that the intrasubject coefficient of variation of $26.7 \%$ for the apparent zero-order rate of ethanol metabolism in men in this study was larger than the intersubject coefficients of variation of 18.4 and $14.8 \%$ calculated from the before and after data of Vesell et al. shown in Table IX. Also, the standard deviation calculated from the differences (after minus before) from the data in Table IX is 0.0554 and the grand mean is 0.198 , giving a coefficient of 
variation of $28.0 \%$. This value agrees quite well with the value of $26.7 \%$ calculated by Wagner and Patel (10). Thus these data tend to indicate that intrasubject variation of the apparent zero-order rate of ethanol metabolism is greater than the intersubject variation. This does not appear to be theoretically sound for a large population, but for the small amount of data available one obtains that answer.

In summary, there is evidence that with many drugs intrasubject variation in elimination rate constants and half-lives of drugs is appreciable and cannot be ignored.

\section{REFERENCES}

1. E. Novak, J. G. Wagner, and D. J. Lamb. Local and systemic tolerance, absorption and excretion of clindamycin hydrochloride after intramuscular administration. Internat. $J$. Clin. Pharmacol. 3: 201-208 (1970).

2. J. G. Wagner, E. Novak, N. C. Patel, C. G. Chidester, and W. L. Lummis. Absorption, excretion and half-life of clinimycin in normal adult males. Am, J. Med. Sci. 256: 25-37 (1968).

3. J. G. Wagner, P. G. Welling, K. P. Lee, and J. E. Walker. In vivo and in vitro availability of commercial warfarin tablets. J. Pharm. Sci. 60: 666-677 (1971).

4. J. G. Wagner. Assay of warfarin: A rebuttal. J. Pharm. Sci. 60: 1272-1273 (1971).

5. J. G. Wagner. Biopharmaceutics and Relevant Pharmacokinetics, Drug Intelligence Publications, Hamilton, Ill., 1971, pp. 188-189.

6. P. G. Welling, K. P. Lee, J. A. Patel, J. E. Walker, and J. G. Wagner. Urinary excretion of ephedrine in man without $p \mathrm{H}$ control following oral administration of three commercial ephedrine sulfate preparations. J. Pharm. Sci. 60: 1629-1634 (1971).

7. J. G. Wagner, J. I. Northam, and W. T. Sokolski. Biological half-lives of the antibiotic lincomycin observed in repetitive experiments in the same subjects. Nature 207: 201-202 (1965).

8. R. A. Buchanan, L. Fernandez, and A. W. Kinkel. Absorption and elimination of ethosuximide in children. J. Clin. Pharmacol. 9: 393-398 (1969).

9. E. S. Vesell, J. G. Page, and G. T. Passonanti. Genetic and environmental factors affecting ethanol metabolism in man. Clin. Pharmacol. Therap. 12: 192-201 (1971).

10. J. G. Wagner and J. A. Patel. Variations in absorption and elimination rates of ethyl alcohol in a single subject. Res. Com. Chem. Pathol. Pharmacol. 4: 61-76 (1972). 